\title{
BMJ Open Size, composition and distribution of human resource for health in India: new estimates using National Sample Survey and Registry data
}

\author{
Anup Karan, ${ }^{1}$ Himanshu Negandhi, ${ }^{2}$ Rajesh Nair, ${ }^{3}$ Anjali Sharma,${ }^{4}$ Ritika Tiwari, ${ }^{4}$ \\ Sanjay Zodpey ${ }^{3}$
}

To cite: Karan A, Negandhi H, Nair R, et al. Size, composition and distribution of human resource for health in India: new estimates using National Sample Survey and Registry data. BMJ Open 2019;9:e025979. doi:10.1136/ bmjopen-2018-025979

- Prepublication history and additional material for this paper are available online. To view these files, please visit the journal online (http://dx.doi. org/10.1136/bmjopen-2018025979).

Received 14 August 2018 Revised 8 December 2018 Accepted 30 January 2019

Check for updates

(C) Author(s) (or their employer(s)) 2019. Re-use permitted under CC BY-NC. No commercial re-use. See rights and permissions. Published by BMJ.

${ }^{1}$ Indian Institute of Public Health, Delhi, Public Health Foundation of India, Gurugram, Haryana, India

${ }^{2}$ Indian Institute of Public Health, Delhi, Public Health Foundation of India, Gurugram, Haryana,

India

${ }^{3}$ Indian Institute of Public Health, Delhi, Public Health Foundation of India, Gurugram, Haryana, India

${ }^{4}$ Academics, Public Health Foundation of India, Gurugram, Haryana, India

Correspondence to

Dr Anup Karan;

anup.karan@iiphd.org

\section{ABSTRACT}

Objectives We provide new estimates on size, composition and distribution of human resource for health in India and compare with the health workers population ratio as recommended by the WHO. We also estimate size of non-health workers engaged in health sector and the size of technically qualified health professionals who are not a part of the health workforce.

Design Nationally representative cross-section household survey and review of published documents by the Central Bureau of Health Intelligence.

Setting National.

Participants Head of household/key informant in a sample of 101724 households.

Interventions Not applicable.

Primary and secondary outcome measures The primary outcome was the number and density of health workers,and the secondary outcome was the percentage of health workers who are technically qualified and the percentage of individuals technically qualified and not in workforce.

Results The total size of health workforce estimated from the National Sample Survey (NSS) data is 3.8 million as of January 2016, which is about 1.2 million less than the total number of health professionals registered with different councils and associations. The density of doctors and nurses and midwives per 10000 population is 20.6 according to the NSS and 26.7 based on the registry data. Health workforce density in rural India and states in eastern India is lower than the WHO minimum threshold of 22.8 per 10000 population. More than $80 \%$ of doctors and $70 \%$ of nurses and midwives are employed in the private sector. Approximately $25 \%$ of the currently working health professionals do not have the required qualifications as laid down by professional councils, while $20 \%$ of adequately qualified doctors are not in the current workforce.

Conclusions Distribution and qualification of health professionals are serious problems in India when compared with the overall size of the health workers. Policy should focus on enhancing the quality of health workers and mainstreaming professionally qualified persons into the health workforce.
Strengths and limitations of this study

- Size and composition, density, and distribution across states, rural-urban and public-private sectors of human resource for health in India have been estimated as of January 2016.

- The study for the first time estimates non-health workers engaged in the health sector and technically qualified health professionals who are not part of the current workforce.

- The registry data of the health professionals in India are inadequately updated, and the National Sample Survey data provide information on a self-reported basis.

- There could be an overlap in the definition and reporting of nurses and midwives in the National Sample Survey data.

\section{INTRODUCTION}

The size and composition of human resource for health (HRH) in India have significantly changed during the last decade. Most existing literature on HRH in India reports that the country is well short of the WHO's recommendation of the minimum threshold of 22.8 skilled health professionals per 10000 population. ${ }^{1-5}$ Recently, WHO, drawing evidence from the Organisation for Economic Co-operation and Development countries, revised the minimum need as 44.5 health professionals per 10000 population. ${ }^{6}$ The Global Health Workforce Alliance and WHO categorised India among the 57 most severe crisis-facing countries in terms of availability of HRH. ${ }^{78}$

The recent health sector reforms in India, particularly since the launch of the National Rural Health Mission, have emphasised on strengthening HRH in the public sector system. 9 For instance, the central and many state governments took proactive steps towards rural posting for public sector doctors. Several states contracted private 
sector practitioners and non-governmental organisations (NGOs) to bridge the manpower gaps at primary health centre levels in rural and suburban areas. ${ }^{9}$ On the supply side, the last one decade and a half witnessed a rise in the medical colleges, nursing institutions and other technical education institutions in medical and paramedical disciplines. $^{10} 11$

Healthcare services in India are offered by a varied range of professionals trained in different specialties of medicine and healthcare. The entire health workforce includes many informal medical practitioners, such as registered medical practitioners (RMPs) (including traditional birth attendants, faith healers, snakebite curers, bonesetters and so on) with or without any formal education or skills training. RMPs are often the first point of contact for treatment for a large proportion of population living in rural and remote areas.

Among the formal healthcare providers, allopathic doctors, which include physicians, surgeons, specialists and medical graduates with a bachelor's or postgraduate specialist diploma or degree, are registered with the Medical Council of India (MCI), and dentists hold a similar degree and are registered with the Dental Council (DC) of India. AYUSH doctors (an indigenous Indian system of medicine comprising Ayurvedic, Yoga, Unani, Siddha and Homeopathy) are bachelor's or postgraduate degree holders in AYUSH. Their registering institution is the Central Council of Indian Medicine or the Central Council of Homoeopathy, and they are authorised to dispense medicines and conduct surgery using their respective fields of specialisation. AYUSH doctors are an integral part of HRH in India as their professions are recognised by a Parliament Act. ${ }^{3-5}$

Another group of health workforce includes subordinate staff which includes, nurses, auxiliary nurses and midwives (ANMs), physiotherapists, and diagnostic and other technicians. Nurses have a diploma in general nursing and midwifery or a bachelor's degree or a postgraduate degree registered with the Indian Nursing Council (INC). ANMs, who mainly work as subordinates to the main nurse, have a diploma in auxiliary nurse midwifery. In addition there are also community health workers with 10 years of formal education and have undergone a short training course. Physiotherapists and diagnostic and other technicians with varied levels of diploma and certificate also perform crucial activities as healthcare workers. ${ }^{5}$

Several studies in the past have estimated the size and composition of HRH in India. ${ }^{1-8}{ }^{12-15}$ However, almost all these studies, except one ${ }^{15}$ are based on dated data, representing the prereforms time period in the health sector. For instance, Rao et $a l^{3}{ }^{3}$ using Census 2001 and the National Sample Survey Organisation (NSSO) 20042005 data, estimated approximately 2.2 million health workers in India, which roughly translate into a density of 20 technical health workers per 10000 population. The study estimated the size of allopathic physicians and surgeons ranging between 0.47 million and 0.67 million.
All these estimates are far lower than the minimum thresholds of 22.8 health workers per 10000 population and 10 doctors per 10000 population. These studies also provided estimates of other health workers such as nurses and midwives, AYUSH doctors, and pharmacists. Other studies have highlighted a lop-sided distribution of HRH across Indian states with comparatively poorer states of the north and east, which have low density of health workers compared with Delhi and South Indian states. $^{35}$ Anand and Bärnighausen ${ }^{1}$ in an India-China comparative study estimated 1.9 million health workers on the basis of the Census 2001 data. The density of doctors and nurses taken together reported in the study is 13.6 per 10000 population, ${ }^{2}$ which is far lower compared with the estimates in other studies. ${ }^{35}$ In a recent study, using the NSSO 2011-2012 data, Rao et al ${ }^{16}$ estimated that there were 2.5 million health workers (density of 20.9 workers) in India. The study also reported that more than half of the total number of health workers are unqualified, and adjusting for the right qualifications leaves India with a density of 9.1 workers per 10000 population. Hazarika, ${ }^{14}$ however, on the basis of government records reported higher number of doctors ( 0.76 million) and nurses (1.6million) for the years 2010 and 2011, respectively. A report by Klynveld Peat Marwick Goerdeler and the Federation of Indian Chambers of Commerce and Industry, using data from the Central Bureau of Health Intelligence, estimated the total size of health workers in India as 4.7 million in year 2015, consisting of 0.9 million doctors, 0.69 million AYUSH doctors and 1.6 million registered nurses. ${ }^{16}$

Earlier studies using prereforms period data do not capture recent changes in the HRH situation. Moreover, only a couple of studies provide data on the situation of HRH gaps at the state level and rural-urban disaggregation. The existing literature does not provide insights into the size of allied health professionals and support staff. Our paper aims to fill these gaps in the literature by providing the latest estimates of HRH as of January 2016 at all-India and state levels and its rural-urban disaggregation. In addition, for the first time we report estimates of the size of non-medical support staff at the country level.

\section{METHODS}

The present study used data from two sources: (1) website of institutions and review of existing reports and literature providing data on registered qualified health professionals, ${ }^{17}$ and (2) the 68th round (July 2011-June 2012) of NSSO data on 'Employment and Unemployment Situation in India'. ${ }^{18}$

\section{Registered qualified health professionals}

The first set of information was collected from the published literature and the websites of MCI, DC, INC, Pharmacy Council of India, Indian Association of Physiotherapists, and the Ministry of Health and Family Welfare (MoHFW). These institutions provide the number of 
registered professionals in the respective fields. However, since the professional councils do not maintain live registers, the information available from them fails to account for health workers leaving the workforce due to death, migration and retirement, or are double-counting workers who have registered in more than one state. We collated these data for different categories of professionals for year 2015.

\section{NSSO data}

The second source of information on health workers is from a household survey on employment and unemployment situation in India conducted by the NSSO every 5 years. The NSSO is a nationally representative multistage, stratified, cluster sample survey which collects information on labour market indicators, along with a range of socioeconomic characteristics of households and individuals. The sample size of the 68th round of NSSO was 101724 households (59700 rural and 42024 urban), covering approximately 457000 persons spread over approximately 12000 villages/urban blocks in the country. The survey collected self-reported information on the types of work of each individual during a reference period of the last 1 year of the survey. Along with a large number of labour market indicators, the survey collected information related to the nature of occupation of workers, categorised by the three-digit National Classifications of Occupation (NCO) 2004 and the fivedigit National Industrial Classification (NIC) 2008, which help identify national-level as well as state-level representative sectoral composition of workers, including workforce engaged in human health activities. However, since NSSO collects the working status of individuals on a self-reported basis, it is possible that many individuals may report themselves as health workers even if they do not possess the requisite qualifications as specified by the MCI, INC and other similar agencies.
Based on these records, we identified seven different categories of health workers, their required educational qualifications and the registering institutions (table 1).

The NSSO survey reports up to two self-reported activities of all persons based on major and short time dispensation criteria separately. For instance, an individual may report being primarily a non-worker, but may be pursuing some economic activities for a short period of time in a reference year. Similarly, an individual primarily engaged in non-medical activities based on primary status might pursue some medical/health activities on a secondary status basis only for a shorter time period in the reference year. We considered both activities of each individual and identified health workers with primary and secondary statuses taken together. The NSSO defines this as usual primary and subsidiary status workers. ${ }^{18}$ Hence, the total health workforce estimates included two distinct groups of individuals: (1) individuals reporting working as health workers according to their primary status and (2) health workers working according to their secondary status but not according to their primary status. Accordingly, the distribution of these workers by rural-urban, publicprivate and so on is based on respective work statuses. This helped in identifying 'not in workforce' persons as those who did not report as a worker as per either their primary or secondary status. Cross-classifying individuals' educational achievements, we identified the size of the technically qualified persons for health service delivery but are not in the workforce.

We used NCO 2004 and NIC 2008 codes to classify health workforce by broad occupation types. Since health workers may be employed within the health sector as well as non-health sector (railways, defence, other non-health enterprises and so on), we considered all sectors of the economy to estimate the HRH

\section{Table 1 Sources of information on registered health professionals}

\begin{tabular}{|c|c|c|}
\hline Health workers & Educational qualification & Registering institution \\
\hline AYUSH practitioners & $\begin{array}{l}\text { Graduates with a bachelor's or postgraduate degree in } \\
\text { Ayurveda, Unani, Siddha or Homoeopathy. }\end{array}$ & Department of AYUSH/MoHFW. \\
\hline Auxiliary nurses and midwives & Diploma in auxiliary nurse midwifery (2-year course). & MoHFW. \\
\hline Pharmacists & Diploma or bachelor's degree course in pharmacy. & Pharmacy Council of India. \\
\hline $\begin{array}{l}\text { Physiotherapists and diagnostic } \\
\text { and other technicians }\end{array}$ & Diploma/certificate in medical allied fields. & $\begin{array}{l}\text { Indian Association of } \\
\text { Physiotherapists and MoHFW. }\end{array}$ \\
\hline
\end{tabular}

AYUSH, indigenous Indian system of medicine comprising Ayurvedic, Yoga, Unani, Siddha and Homeopathy; MoHFW, Ministry of Health and Family Welfare. 
size. Further, the health sector also employed a large number of non-health workers such as managers, accountants, clerks, drivers and other similar support staff. We estimated the size of all those non-health workers employed in the health sector. We used NCO (three-digit) and NIC (five-digit) codes to identify three major categories of workers:

- Individuals trained in medical, paramedical and related activities working within the health sector of the economy (health workers in the health sector).

- Individuals trained in medical, paramedical and related activities working in the non-health sector of the economy (health workers in the non-health sector).

- Individuals not trained in medical, paramedical and related activities working within the health sector of the economy only as support staff (non-health workers in the health sector).

Here we want to clarify that all unregistered personnel dispensing medical advice and medicines, including personnel whose qualifications are incomplete, are included in the first two categories. However, we also present the estimates by excluding those who are inadequately qualified. The third category represents non-medical staff such as managers, clerks, accountants, sanitation workers and so on. The types of health workforce identified in the NSSO survey along with the NCO and NIC codes are presented in online supplementary appendix, section I.

The existing NCO and NIC codes in the 2011-2012 survey could not identify disaggregated numbers of health professionals by allopathic doctors, AYUSH doctors and dentists in the non-health sector, although the same were identified within the health sector (first category). Since the previous NSSO surveys used the NCO 1968 code, the same disaggregation in non-health sector was available in the 2004 survey. We used the ratio of allopathic doctors, dentists and AYUSH doctors to the total health professionals to segregate the numbers of allopathic doctors, dentists and AYUSH doctors only in the non-health sector. We reported segregated numbers for the three categories of the HRH (allopathic doctors, dentists and AYUSH doctors) only at the national level. Also, within the AYUSH, the latest NSSO data do not support reliable estimates on different components such as Ayurveda, Unani, Siddha, naturopathy and homoeopathy.

The two sources (registry and NSSO data) identify comparable categories of health professionals except for the two categories where comparable estimates were not available. One of these is the group categorised as 'health associate professionals' in the NSSO consisting of health assistants, sanitarians, dietitians and nutritionists, optometrists and opticians, dental assistants, physiotherapy associates, pharmacist assistants, and so on. We did not find comparable estimates on these workers from other sources. Similarly, the number of ANMs is available from the records of the MoHFW but could not be identified in the NSSO because of the overlap of NCO codes. ${ }^{3}$

NSSO data contain self-reported information on educational levels completed by each individual. We compared educational achievements of health workers (reported in the NSSO data) with the required qualifications as recommended by agencies such as MCI for doctors and INC for nurses and auxiliary nurses.

Although NSSO data do not provide information on rural-urban break-up of workplace of workers, we used information on rural-urban place of residence of workers to compare the proportional distribution of all population and health workforce across rural and urban settings. In general, the rural-urban place of residence of health workers can proxy the availability of HRH in the respective areas.

In order to estimate the total number of health workforce as of January 2016, we applied the worker participation rate (WPR) estimated from NSSO 2011-2012 to the projected population as of 1 January 2016 using the cumulative annual growth rate of the population between 2001 and 2011 population censuses. The projections were done at disaggregated levels-male and female living in rural and urban areas separately in all states. The final estimates of HRH were arrived at using the formula in equation (1).

$$
H W_{h a}=p o p l_{i j k} 2016 * W P R_{h a}
$$

where ' $H W_{h a}$ ' represents health workers from categories 'a' (representing doctors, dentists, AYUSH, nurses and so on); $p o p l_{i j k} 2016$ is the projected population as of January 2016 and $W P R_{h a}$ is worker participation rate for each category in years 2011-2012. Estimation of WPR in each category of workers was arrived at using equation (2).

$$
W P R_{h a}=N / p_{p o p} l_{i j k} 2011-12
$$

where $N$ is the number of workers in each category (see online supplementary appendix, section II for the details on the methods of projection).

We assumed the WPR of health workers in year 2016 to be the same as estimated from the NSSO 2011-2012 data. Although WPR has declined over the years between 20092010 and 2011-2012, the decline has been less than 1\%, and most of the decline has been realised in rural areas and among women. We assumed that WPR among health professionals has not declined significantly since 2011-2012.

\section{Patient and public involvement}

The two data sources (NSSO and registry institutions) collected information from individuals through sample survey and registration process, respectively. However, the present study only accessed anonymised data available in public domain and does not involve patient and/or public in research design, outcome measures, data analysis and interpretation of results.

\section{RESULTS}

To start with we present a brief demographic and employment status of health workers estimated from the NSSO 
Table 2 Total number of health workers by broad categories as of 1 January 2016

\begin{tabular}{|c|c|c|c|}
\hline $\begin{array}{l}\text { Health worker } \\
\text { category }\end{array}$ & $\begin{array}{l}\text { Estimates } \\
\text { based on } \\
\text { NSSO as of } \\
1 \text { January } \\
2016\end{array}$ & $\begin{array}{l}\text { Registered, } \\
2015^{\star}\end{array}$ & $\begin{array}{l}\% \text { of } \\
\text { estimated to } \\
\text { registered }\end{array}$ \\
\hline Allopathic doctor & 770277 & 936488 & 82.25 \\
\hline Dental practice & 95959 & 154436 & 62.14 \\
\hline AYUSH & 530919 & 744563 & 71.31 \\
\hline $\begin{array}{l}\text { Physiotherapy, } \\
\text { diagnostic and } \\
\text { others }\end{array}$ & 86508 & 60000 & 144.18 \\
\hline $\begin{array}{l}\text { Nursing and } \\
\text { midwife }\end{array}$ & 1317669 & 1673338 & 78.74 \\
\hline Pharmacist & 214744 & 664176 & 32.33 \\
\hline $\begin{array}{l}\text { Health associate } \\
\text { professional } \dagger\end{array}$ & 811744 & NA & NA \\
\hline ANM & NA & 789740 & NA \\
\hline All & 3827820 & 5022741 & 76.21 \\
\hline
\end{tabular}

Sources: column 2: authors' estimates using unit-level data of the NSSO 2011-2012; column 3: CBHI 2017. ${ }^{18}$

${ }^{*}$ Registered with $\mathrm{MCl} / \mathrm{INC}$, Association and MoHFW records. †Includes health assistants, sanitarians, dietitians and nutritionist, optometrists and opticians, dental assistants, physiotherapy associates, pharmacist assistants, and so on. ANM, auxiliary nurses and midwives; AYUSH, indigenous Indian system of medicine comprising Ayurvedic, Yoga, Unani, Siddha and Homeopathy; CBHI, Central Bureau of Health Intelligence; INC, Indian Nursing Council; $\mathrm{MCl}$, Medical Council of India; MoHFW, Ministry of Health and Family Welfare; NA, not available; NSSO, National Sample Survey Organisation.

data (online supplementary appendix table AI). More than $58 \%$ of all health workers are male. The proportion of male is higher in the allopathic, AYUSH and dental categories, and lower in the nurse and midwife category. Approximately $80 \%$ of all health workers are in the 25-60years age group. Approximately $30 \%$ of all health workers, $15 \%$ among allopathic doctors, reported their educational level below the higher secondary level. Most of the health workers reported to be employed as regular wage earners $(57 \%)$. However, as high as $63 \%$ of allopathic and $88 \%$ of AYUSH doctors reported themselves as self-employed.

\section{Size and composition}

The total size of health workforce estimated from NSSO is approximately 3.8 million as of January 2016 (table 2 ).

The NSSO estimates are about 1.2 million lower than the total number of health professionals registered with different councils and associations. The total number of registered doctors and nurses with MCI and INC, respectively, was 0.94 million and 1.67 million, respectively, in year 2015 as against 0.77 million doctors and 1.32 million nurses and midwives estimated from NSSO in year 2016. In addition, health associate professionals as reported in the NSSO data are estimated at 0.8 million. The total number of ANMs, available only from the MoHFW, is approximately 0.79 million.

In addition, the NSSO estimates include approximately 1.25 million non-health workers (other support staff) employed in the health sector (table 3 ).

More than one-fifth $(0.26$ million $)$ of all non-health workers engaged in health sector are administrative support staff such as clerks, cashiers, teller and so on. Personal care staff such as housekeeping and restaurant service workers, personal care, protective service, and so on constituted $17 \%$ (0.21 million) and garbage collectors and related sanitation workers constituted $13 \%$ of all non-health workers within the health sector. Motor drivers constituted more than $5 \%$ of all non-health workers in the health sector.

\section{Density}

Estimates from NSSO translate to approximately 29 health workers per 10000 population if all HRHs are taken into consideration (figure 1). Nurses and midwives had the largest share (their density being 10 and 12.7 per 10000 population on the basis of NSSO and INC, respectively) in the total health workforce.

Considering only doctors (including AYUSH) and nurses and midwives, the density of health workers is 20.6 per 10000 population according to the NSSO estimates and 26.7 per 10000 population according to the registry data. Estimates from NSSO are marginally below and the registry data are considerably above the WHO's minimum threshold of 22.8 workers per 10000 population. However, if we consider ANM as part of the trained health workers, the density turns out to be close to 30 per 10000 population. NSSO numbers indicate that there are 10 nurses and midwives per 10000 population. This translates to 1.7 nurses and midwives per allopathic doctors as against the High Level Expert Group (HLEG) recommendation of two nurses and one ANM per allopathic doctor. ${ }^{19}$ The registered numbers too reflect almost the same ratio between nurses and midwives and allopathic doctors.

When the estimates on total health workers from NSSO are adjusted for qualification, the density is reduced from 29 to 16 per 10000 population (table 4). For allopathic doctors, $24 \%$ had inadequate or no medical training. Adjusting for this proportion, the density of allopathic doctors at the country level declines from 5.9 to 4.5 per 10000 population. Similarly, the proportion of nurses and midwives per 10000 population drops down to 4.2 when adjusted with the required level of education and training.

\section{Distribution across states, rural-urban and public-private}

Most of the central and eastern Indian states have low density of health workers, ranging from approximately 23 per 10000 population in Bihar and north-east states other than Assam, to as low as 7 per 10000 population in Jharkhand. The only South Indian states reflecting 
Table 3 Number, percentage distribution and per 10000 population of other support workers in the health sector estimated from NSSO as of 1 January 2016

\begin{tabular}{lccl}
\hline Types of workers & $\begin{array}{l}\text { Total number of } \\
\text { support workers in } \\
\text { the health sector }\end{array}$ & $\begin{array}{l}\text { Distribution } \\
\text { of all support } \\
\text { workers (\%) }\end{array}$ & $\begin{array}{l}\text { Support workers in the } \\
\text { health sector per 10000 } \\
\text { population }\end{array}$ \\
\hline Clerks, cashiers, tellers and so on & 261048 & 21.0 & 1.98 \\
\hline Personal care, housekeeping and so on & 212499 & 17.1 & 1.62 \\
\hline Garbage collectors and related labourers & 161923 & 13.0 & 1.23 \\
\hline Life science professionals & 87108 & 7.0 & 0.66 \\
\hline Directors and chief executives and managers & 79545 & 6.4 & 0.60 \\
\hline Motor drivers & 64216 & 5.2 & 0.49 \\
\hline Other workers in the health sector & 58871 & 4.7 & 0.45 \\
\hline Messengers, porters, door keepers and related & 52854 & 4.2 & 0.40 \\
\hline Physical and engineering science technicians & 50884 & 4.1 & 0.39 \\
\hline Chemical products and machine operators & 36211 & 2.9 & 0.28 \\
\hline Precision workers in metal and related materials & 33954 & 2.7 & 0.26 \\
\hline Mathematicians, statisticians and computer professionals & 33365 & 2.7 & 0.25 \\
\hline Architects, engineers and related & 25265 & 2.0 & 0.19 \\
\hline General and department managers & 24634 & 2.0 & 0.19 \\
\hline Mechanics, fitters, finishers and so on & 19805 & 1.6 & 0.15 \\
\hline Business professionals & 19545 & 1.6 & 0.15 \\
\hline Teaching professionals and associates & 18308 & 1.5 & 0.14 \\
\hline Physicists, chemists and related & 5844 & 0.5 & 0.04 \\
\hline Total & 1245878 & 100 & 9.47 \\
\hline
\end{tabular}

Source: authors' estimates using unit-level data of the National Sample Survey Organisation 2011-2012.

lower density than the all-India average (29) is Andhra Pradesh (25), and the only eastern Indian state having higher density than the all-India average is West Bengal (36). The highest concentration of health workers is in Delhi (67), followed by Kerala (66), Punjab (52) and
Haryana (44) (figure 2A). Considering only doctor, nurse and midwife density per 10000 population, the numbers in Delhi and Kerala are far higher compared with other states, with Bihar along with Jharkhand occupying the lowest position (figure $2 \mathrm{~B}$ ).



Note: * includes health assistant, sanitarian, dietician and nutritionist, optometrists and opticians, dental assistants, physiotherapy associates, pharmacist assistant etc.

Source: Authors' estimates using unit level data of the NSSO 2011-12 and Registry data

Figure 1 Health worker density: all-India number (of health workers per 10000 population). ANM, auxiliary nurses and midwives; AYUSH, indigenous Indian system of medicine comprising Ayurvedic, Yoga, Unani, Siddha and Homeopathy; NSSO, National Sample Survey Organisation. 
Table 4 Percentage of health professionals without the requisite qualifications and the adjusted estimates of health workers, total number and per 10000 population

\begin{tabular}{llcc}
\hline Health worker category & $\begin{array}{l}\text { Health professional } \\
\text { not with requisite } \\
\text { qualifications (\%) }\end{array}$ & $\begin{array}{l}\text { Total number of HRH } \\
\text { after adjusting for } \\
\text { education }\end{array}$ & $\begin{array}{l}\text { Density of HRH per 10000 } \\
\text { population after adjusting for } \\
\text { education }\end{array}$ \\
\hline Allopathic physician & 24 & 585411 & 4.5 \\
\hline Dental practice & 8 & 88282 & 0.7 \\
\hline AYUSH & 21 & 419426 & 3.2 \\
\hline Physiotherapy, diagnostic and others & 45 & 47579 & 0.4 \\
\hline Nursing and midwife & 58 & 553421 & 4.2 \\
\hline Health associate professional† & 62 & 308463 & 2.3 \\
\hline Pharmacist & 62 & 81603 & 0.6 \\
\hline Total & 54 & 2084185 & 15.8 \\
\hline
\end{tabular}

Source: authors' estimates using unit-level data of National Sample Survey Organisation 2011-2012.

*The level of required qualifications considered for doctors (allopathic, dental and AYUSH) was graduate/postgraduate in medicine, for nurse and midwife higher secondary with technical education in medicine or related field, and for others higher secondary with technical education in paramedical related fields. ${ }^{15}$

†Includes health assistants, sanitarians, dietitians and nutritionists, optometrists and opticians, dental assistants, physiotherapy associates, pharmacist assistants, and so on.

AYUSH, indigenous Indian system of medicine comprising Ayurvedic, Yoga, Unani, Siddha and Homeopathy; HRH, human resource for health.

The density of physician and surgeons (including AYUSH and dental) per 10000 population is as low as 1.8 in Assam and 1.9 in Himachal Pradesh (table 5).

A

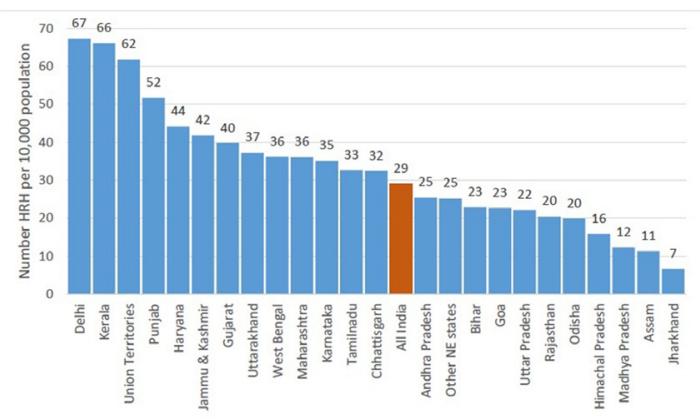

B

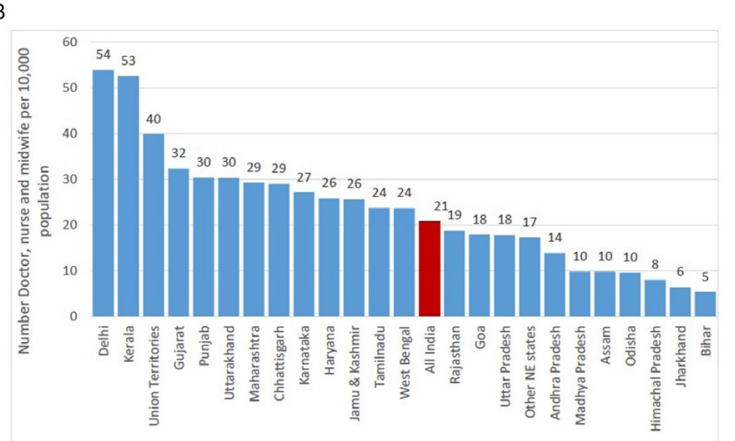

Source: Authors' estimates using unit level data of the NSSO 2011-12

Figure 2 (A) Total health worker density: major states (per 10000 population). (B) Physician, surgeon and nurse density: major states (per 10000 population). HRH, human resource for health; NE, north-east; NSSO, National Sample Survey Organisation.
The density of allopathic doctors is also lower than five in the states of Bihar, Jharkhand and Rajasthan. Delhi has the highest density of doctors (34), but the density of nurse and midwife is the highest (38) in Kerala. The HLEG recommendation for the doctor to nurse ratio in India is $1: 3{ }^{19}$ The states with acute adverse ratio (less than 1:1) of nurse to doctor are Bihar, Chhattisgarh, Goa, Haryana, Jammu and Kashmir, Karnataka, Madhya Pradesh, Maharashtra, Odisha, Punjab, Uttar Pradesh and West Bengal.

The uneven distribution of health workers is also reflected across rural-urban settings. Although rural India constituted approximately $71 \%$ of the total population in 2016, only $36 \%$ of all health workers are in rural areas (figure 3). This proportion is a little lower for health associates and assistants and pharmacists. The proportions of doctor and nurses in rural areas are $34 \%$ and $33 \%$, respectively.

Further, the bulk of the total health workforce is employed in the private sector (figure 4). The proportion employed in the private sector is far higher for doctors compared with nurse and midwife and other health workers. In case of AYUSH and dental practitioners, the share of the public sector is less than $10 \%$. However, approximately $45 \%$ of nurses and midwives are employed in public sector institutions (figure 4). Further, the private health sector in India consists of a wide range of service providers, ranging from 'for-profit' hospitals, 'not-for-profit' (NGO, charitable institutions, trusts and so on) institutions and private individual practitioners. ${ }^{120}$ The distribution of all health workers by types of institutions reflects that an overwhelming majority (53\%) of these workers are self-employed in sole proprietorship 
Table 5 Health worker density (per 10000 population) in states in India

\begin{tabular}{|c|c|c|c|c|}
\hline State & Doctors* & $\begin{array}{l}\text { Health } \\
\text { associates } \dagger\end{array}$ & $\begin{array}{l}\text { Nurses } \\
\text { and } \\
\text { midwives }\end{array}$ & All \\
\hline Andhra Pradesh & 5.9 & 11.5 & 7.9 & 25.4 \\
\hline Assam & 1.8 & 1.0 & 8.0 & 11.3 \\
\hline $\begin{array}{l}\text { Other north-east } \\
\text { statesł }\end{array}$ & 6.7 & 7.8 & 10.6 & 25.1 \\
\hline Bihar & 3.3 & 17.5 & 2.0 & 22.9 \\
\hline Chhattisgarh & 18.3 & 3.5 & 10.7 & 32.4 \\
\hline Delhi & 34.4 & 13.4 & 19.5 & 67.3 \\
\hline Goa & 11.3 & 4.8 & 6.5 & 22.7 \\
\hline Gujarat & 5.8 & 7.4 & 26.5 & 39.8 \\
\hline Haryana & 16.8 & 18.3 & 9.0 & 44.1 \\
\hline Himachal Pradesh & 1.9 & 7.9 & 6.0 & 15.9 \\
\hline Jammu \& Kashmir & 14.7 & 15.7 & 11.0 & 41.8 \\
\hline Jharkhand & 3.0 & 0.3 & 3.3 & 6.7 \\
\hline Karnataka & 17.1 & 8.0 & 10.0 & 35.1 \\
\hline Kerala & 14.5 & 13.4 & 38.2 & 66.0 \\
\hline Madhya Pradesh & 6.3 & 2.5 & 3.5 & 12.3 \\
\hline Maharashtra & 19.7 & 6.7 & 9.6 & 36.0 \\
\hline Odisha & 7.4 & 10.3 & 2.1 & 19.9 \\
\hline Punjab & 17.8 & 21.3 & 12.5 & 51.7 \\
\hline Rajasthan & 4.5 & 1.4 & 14.3 & 20.4 \\
\hline Tamilnadu & 8.6 & 8.7 & 15.2 & 32.6 \\
\hline Uttar Pradesh & 13.8 & 4.0 & 3.9 & 22.1 \\
\hline Uttarakhand & 11.6 & 6.9 & 18.7 & 37.2 \\
\hline West Bengal & 16.9 & 12.5 & 6.7 & 36.1 \\
\hline Union Territories§ & 12.3 & 21.8 & 27.6 & 61.7 \\
\hline All India & 11.3 & 8.4 & 9.4 & 29.1 \\
\hline
\end{tabular}

Source: authors' estimates using unit-level data of National Sample Survey Organisation 2011-2012.

*Includes allopathic, AYUSH and dental practitioners.

†Includes health assistants, sanitarians, dietitians and nutritionists, optometrists and opticians, dental assistants, physiotherapy associates, pharmacists, and pharmaceutical assistants. †Includes six north-east Indian states: Arunachal Pradesh, Meghalaya, Mizoram, Nagaland, Sikkim and Tripura.

§Includes Andaman and Nicobar Islands, Dadar and Nagar Haveli, and Lakshadweep.

AYUSH, indigenous Indian system of medicine comprising Ayurvedic, Yoga, Unani, Siddha and Homeopathy.

or partnership entity. Only $6 \%$ of all health workers are employed in big corporate companies with public or private limited status (figure 5).

Lastly, our analysis reveals that a sizeable proportion of technically qualified individuals are not in the existing health workforce. We estimated a percentage of all adults (age 15 years and above) with education in medical-related and other fields who are currently not in workforce (table 6).

In general, $45 \%$ of all adult individuals are not in the workforce. The proportion of individuals with medical

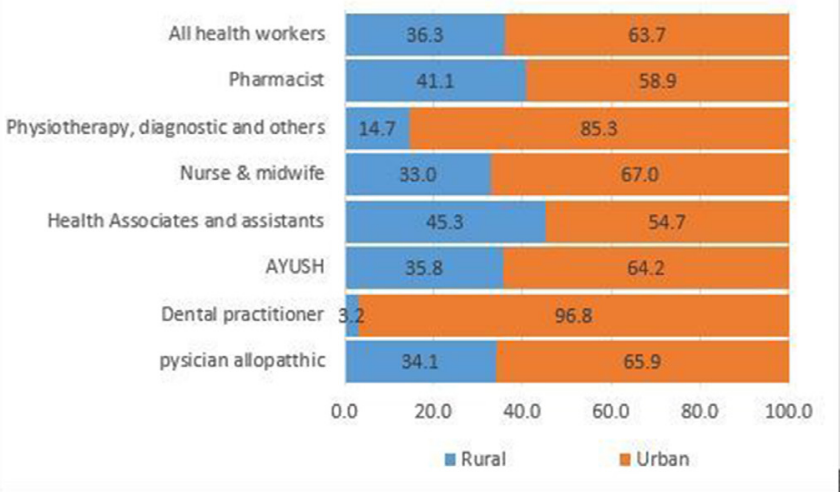

Source: Authors' estimates using unit level data of the NSSO 2011-12

Figure 3 Rural-urban distribution (\% share) of health workers. AYUSH, indigenous Indian system of medicine comprising Ayurvedic, Yoga, Unani, Siddha and Homeopathy; NSSO, National Sample Survey Organisation.

or related degrees but not in existing workforce is $19 \%$ for 'graduate in medicine' and $31 \%$ for 'Diploma/Certificate in medicine'. These proportions are $26 \%$ and $46 \%$, respectively, for women. In case of vocational training in health and paramedical services, however, a higher proportion of men $(38 \%)$ compared with women $(26 \%)$ are out of workforce.

\section{DISCUSSION}

The study presents updated estimates of HRH in India as of January 2016. In addition to health workers directly involved in service delivery, for the first time we estimated the size and composition of support health workers and non-health workers employed within the health sector. Two major sources of data, employment and unemployment survey of NSSO 2011-2012 and registration of health professionals with institutions until 2015, largely reflect similar results, except a couple of additional categories of health workers reported across the two sources.

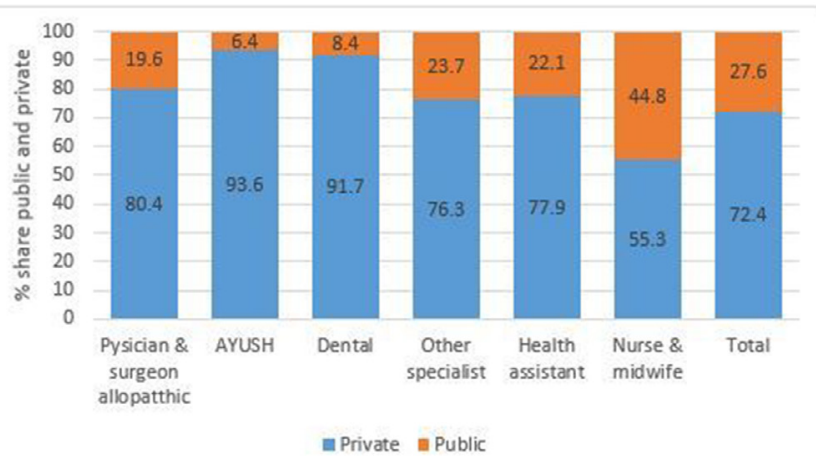

Source: Authors' estimates using unit level data of the NSSO 2011-12

Figure 4 Public-private distribution (\% share) of health workers. AYUSH, indigenous Indian system of medicine comprising Ayurvedic, Yoga, Unani, Siddha and Homeopathy; NSSO, National Sample Survey Organisation. 


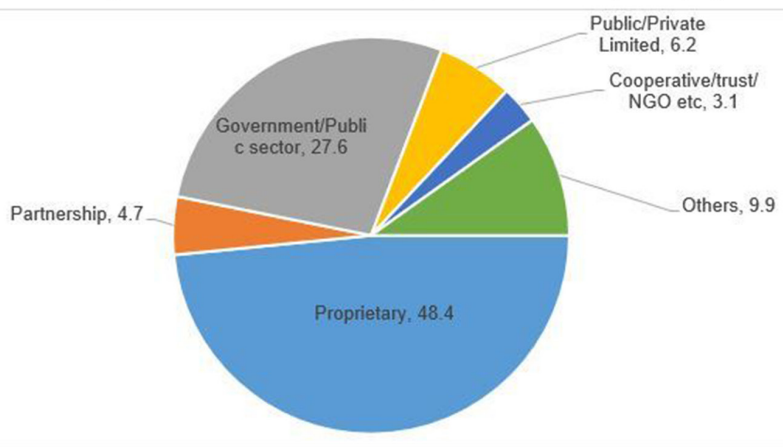

Source: Authors' estimates using unit level data of the NSSO 2011-12

Figure 5 Percentage distribution of health workers by type of enterprise they are employed with. NGO, nongovernmental organisation; NSSO, National Sample Survey Organisation.

In general, estimates from NSSO are lower in comparison with those from the registry data. There are several possible explanations, which include the following: (1) many registered professionals are unemployed and are looking for suitable jobs, (2) many registered professionals have migrated out of the country, (3) they may be out of labour force by choice and not looking for any employment (mostly women and due to old age), and (4) many of these registered professionals may not be alive any more. This calls for a need of a regular updating and maintenance of live registers of health professionals so that adequate information on the size of HRH could be available on a real-time basis.

Our estimates from NSSO are higher compared with a similar study using the NSSO data ${ }^{15}$ mainly because we considered all health workers employed either as their principal or subsidiary activity status. Combining principal and subsidiary statuses provides larger estimates

Table 6 Percentage of all adult individuals (age 15 years and above) with different levels of education not in workforce

\begin{tabular}{llll}
\hline Level of education & Persons & Male & Female \\
\hline $\begin{array}{l}\text { Graduate in medicine } \\
\text { Graduate in other }\end{array}$ & 19.2 & 16.3 & 25.7 \\
$\begin{array}{l}\text { Diploma/Certificate in } \\
\text { medicine }\end{array}$ & 30.9 & 16.6 & 69.2 \\
$\begin{array}{l}\text { Diploma/Certificate in } \\
\text { other }\end{array}$ & 29.6 & 21.8 & 54.5 \\
$\begin{array}{l}\text { Vocational training in } \\
\text { health and paramedical } \\
\text { services }\end{array}$ & 9.9 & 37.9 & 26.3 \\
$\begin{array}{l}\text { Other technical degree } \\
\text { No technical degree* }\end{array}$ & 23.3 & 17.3 & 39.6 \\
\hline \begin{tabular}{l} 
Total \\
\hline
\end{tabular} & 44.7 & 20.8 & 70.0 \\
\hline
\end{tabular}

Source: authors' estimates using unit-level data of National Sample Survey Organisation 2011-2012.

*Including illiterate. compared with only principal status workers as reported in Rao $e a^{15}$ using the same source of data. The largest difference we find is for AYUSH workers: an overwhelmingly large proportion of them report as health workers in subsidiary status capacity only.

The density of the total health workers is estimated to be 29 per 10000 population based on NSSO and 38 per 10000 population based on the registration data. Even by only considering service delivery workers, the density estimates in this study are close to WHO's minimum threshold of 22.8 health workers per 10000 population. However, our estimates also reveal an alarmingly large presence of unqualified health professionals in the workforce. Adjusting for adequate qualifications of health workers reduced the density from 29 to 16 health workers per 10000 population. The presence of unqualified health professionals in the health system is not unique in India. Many low-income and middle-income countries, particularly China and Africa, report a large presence of such professionals. ${ }^{21}$ Unqualified health professionals are usually the first point of contact for rural and poor population in case of any ailment. Quacks, traditional healers, bonesetters and so on fall in this category.

Apart from India 'quacks' exist in other countries as well. In South Africa, bogus doctors or quacks are increasingly seeping into the health system. ${ }^{21}$ Several cases have been noted for where people had impersonated as doctors and pharmacists. ${ }^{21}$ With increasing cases of fake doctors in the UK, checks are regularly conducted on foreign doctors. ${ }^{22}$ Similar problem of quacks persists in countries like Bangladesh, ${ }^{23}$ China, ${ }^{24}$ Uganda $^{25}$ and Australia. ${ }^{26}$

A few countries have attempted to mainstream these health professional by bringing them in the fold of RMPs. One such category in India is Dai (female birth attendant), who may also be registered with the government and is allowed to deliver service. Another example of mainstreaming these workers is registering them as paramedical persons by a few state governments. However, so far there is no clear policy in India related to these workers, and many of these health workers continue working without any formal system in place.

We for the first time presented two additional categories of workers directly or indirectly engaged in the activities related to human health. These two categories of workers are (1) health assistants and associates and (2) other support staff engaged in administrative, managerial and other support activities. Health associates and assistants directly support other health workers involved in service delivery. This group (0.81 million as of January 2016) included health assistants, sanitarians, dietitians and nutritionists, optometrists and opticians, dental assistants, physiotherapy associates, pharmacist assistants, and so on. The second group (1.25 million) included clerks, cashiers, tellers, housekeeping and restaurant service workers, personal care, protective service staff, garbage collectors, other sanitation workers, and so on. These support staff perform crucial roles which are imbedded in the overall health service delivery. 
Our findings from NSSO clearly show the dominance of the private sector in the total HRH. In general, a little over $50 \%$ of all doctors in India are produced by government medical colleges, and more than $80 \%$ of them are employed in private institutions or work as private practitioners. ${ }^{20} 27$ Although it cannot be argued that all those who studied in public institutions should only work in the public sector, it may not be out of order to expect that professionals passing out from public institutions must be sufficiently sensitive to public health issues and may extend their services at least in some proportion to public sector facilities. In recent years, the Government of India and a few state governments have been recommending for a few years of rural posting for newly passed out health professionals. Also, governments both at the central and state levels have come out with strategies to use the services of private health professionals in public sector facilities.

In general, we find that although the overall size of health workers in India is lower than many developed countries, these numbers are close to the WHO minimum threshold of 22.8 doctors and nurses per 10000 population. Recently WHO has revised the minimum threshold to 44.5 per 10000 population. This higher threshold is based on the experiences of developed countries, and India should certainly aspire to achieve this in the near future.

However, there are serious problems related to the distribution of HRH across Indian states and rural-urban settings. The bulk of doctors and nurses is located in major cities, leaving a significant gap in rural areas and in poorer states.

Further, a sizeable proportion of technically qualified individuals are not in the workforce. A large proportion of them are women. The government has taken up several initiatives in recent years, including enhanced retirement age and suitable working conditions for female workers, to mainstream these technically qualified persons.

Our analysis has a few obvious limitations. Apart from the fact that the registry data of the health professionals are inadequately updated, NSSO data provide information on a self-reported basis. However, both the sources taken together may provide a range of availability of health workers in India. We have used the WPR of 20112012 from the NSSO data to estimate health workers as of January 2016. NSSO data are not available so far after 2011-2012. If the WPR of health workers declines after 2011-2012, our estimates from NSSO are likely to be upwardly biased. Another limitation of the study is overlap in the definition and reporting of nurses and midwives in the NSSO data. Further, many health professionals may work in the public and private sectors and rural and urban areas simultaneously. The data and methods used in our study are not capable of capturing this phenomenon fully.

\section{CONCLUSION}

Distribution and qualification of health professionals are serious problems in India when compared with the overall size of the health workers. In contrast, a large proportion of technically qualified health professionals are not in the current workforce. Any HRH policy needs to consider these points while considering changes/reforms in the existing policy. Policy should focus on enhancing the quality of health workers and mainstreaming professionally qualified persons into the health workforce.

Contributors AK, HN and SZ conceptualised the study. AK, AS, HN, RN and RT conducted data analysis and review of literature. AK, HN and SZ prepared the first draft. All authors contributed to review and revision of the first draft and approved the final version.

Funding This article is part of a research project funded by John Snow India (grant number JSI/India/GG/01/01/2016) to the Public Health Foundation of India.

Disclaimer The funder has no role in the design of the study, collection of data, interpretation of results, manuscript preparation and decision to publish the article in any journal.

Competing interests None declared.

Patient consent for publication Not required.

Ethics approval Ethical clearance for this study was obtained from the Institutional Ethics Committee (IEC) of the Indian Institute of Public Health Delhi under 'Expedited Review'.

Provenance and peer review Not commissioned; externally peer reviewed.

Data sharing statement The data set used in the study are publicly available from the National Sample Survey Organisation and the Medical and Nursing Council of India. Anyone can access this data set either by paying the requisite fee or by making request for free access.

Open access This is an open access article distributed in accordance with the Creative Commons Attribution Non Commercial (CC BY-NC 4.0) license, which permits others to distribute, remix, adapt, build upon this work non-commercially, and license their derivative works on different terms, provided the original work is properly cited, appropriate credit is given, any changes made indicated, and the use is non-commercial. See: http://creativecommons.org/licenses/by-nc/4.0/.

\section{REFERENCES}

1. Anand S, Bärnighausen T. Human resources and health outcomes: cross-country econometric study. Lancet 2004;364:1603-9.

2. Anand S, Fan V. The health workforce in India. Geneva: World Health Organization; 2016 (Human Resources for Health Observer Series No.16. http://www.who.int/hrh/resources/16058health_workforce India_pdf?ua=1 (accessed 30 January 2017).

3. Rao KD, Bhatnagar A, Berman P. So many, yet few: Human resources for health in India. Hum Resour Health 2012;10:19.

4. Ramani S, Rao KD, Ryan M, et al. For more than love or money: attitudes of student and in-service health workers towards rural service in India. Hum Resour Health 2013;11:58.

5. Rao M, Rao KD, Kumar AKS, et al. Human resources for health in India. The Lancet 2011;377:587-98.

6. World Health Organisation. Global strategy on human resources for health: workforce 2030. Geneva: World Health Organization, 2016.

7. Campbell J, Dussault G, Buchan J, et al. A universal truth: no health without a workforce. Forum Report, Third Global Forum on Human Resources for Health, Recife, Brazil. Geneva: Global Health Workforce Alliance and World Health Organization, Geneva, 2013.

8. World Health Organisation. Not Enough Here- Too Many ThereHealth Workforce in India. Geneva: World Health Organisation, Country Office for India, 2007.

9. Ministry of Health and Family Welfare. National Health Policy. Ministry of Health and Family Welfare, Government of India: New Delhi, 2017.

10. Sharma K, Zodpey S, Quazi SZ, et al. Mapping and opportunities of human resource capacity building initiatives for HIV/AIDS in India. Ann Trop Med Public Health 2013;6:30-41.

11. Public Health Foundation of India. From Paramedics to Allied Health Professionals: Landscaping the Journey and Way forward. National 
Initiative for Allied Health Sciences. A Report Commissioned by the Ministry of Health and Family Welfare. Government of India: New Delhi, 2012.

12. National commission on Macroeconomics and Health. Report of The National commission on Macroeconomics and Health. New Delhi: Ministry of Health and Family Welfare, Government of India, 2005.

13. Anand S, Poz MD, Gupta N, et al. Measuring Health Workforce Inequalities: Methods and Application to China and India. Geneva: World Health Organization, 2010.

14. Hazarika I. Health workforce in India: assessment of availability, production and distribution. WHO South East Asia J Public Health 2013;2:106-12.

15. Rao KD, Shahrawat R, Bhatnagar A. Composition and distribution of the health workforce in India: estimates based on data from the National Sample Survey. WHO South East Asia J Public Health 2016;5:133-40.

16. KPMG-FICCI. Healthcare: the neglected GDP driver-need for a paradigm shift. KPMG-FICCI: New Delhi [Internet], 2015.

17. Central Bureau for Health Intelligence. Directorate General of Health Services, Ministry of Health and Family Welfare, Government of India. 2017. Available at http://www.cbhidghs.nic.in/E-Book\%20HTML2017\%20PART-l/files/assets/basic-html/page-1.html.

18. National Sample Survey Organisation (NSSO). NSS Report No. 554/68/10/1: chapter II, Employment and Unemployment Situation in India, 2009-10. National Sample Survey Organisation, Ministry of Statistics and Programme Implementation. New Delhi: Government of India, 2014.
19. High Level Expert Group (HLEG) Report 2011. High level expert group report on universal health coverage in India. New Delhi: Public Health Foundation of India, 2011. Submitted to the Planning Commission, Government of India.

20. Mackintosh M, Channon A, Karan A, et al. What is the private sector? Understanding private provision in the health systems of low-income and middle-income countries. The Lancet 2016;388:596-605.

21. Davids B. More bogus doctors slipping through. Independent Online 2017.

22. Forsyth L. Urgent checks on foreign doctors after fake NHS psychiatrist worked for 22 years. Mirror 2018.

23. El-Saharty S, Sparkes SP, Barroy H, et al. The path to universal health coverage in Bangladesh: bridging the gap of human resources for health. Washington DC: The World Bank, 2015.

24. Yuan L. Older Miao people and rural health policy in China: barriers and opportunities of older miao people under the new rural cooperative medical scheme: LAP Lambert Academic Publishing, 2012.

25. IntraHealth. Five techy solutions for health systems around the World. Washington DC: IntraHealth International, Inc, 2014.

26. Dwyer J. Australian patients vulnerable to quacks: The Sydney Morning Herald, 2017.

27. Karan A, Selvaraj S, Mahal A. Moving to universal coverage? Trends in the burden of out-of-pocket payments for health care across social groups in India, 1999-2000 to 2011-12. PLoS One 2014;9:e105162. 